\title{
A PROPOSED ECOSYSTEM OF MANUFACTURE METHOD TO REDUCE GLOBAL ENVIRONMENTAL IMPACT OF THE STEEL INDUSTRY*
}

Ronaldo Santos Sampaio 1

\begin{abstract}
This paper call attention to increasing ratio of oxygen depletion from atmosphere besides the global worries about $\mathrm{CO}_{2}$ concentration increase in the atmosphere. It highlights the big mistake in considering Carbon Capture and Storage, CCS, as a way to reduce the increasing concentration of $\mathrm{CO}_{2}$ in the atmosphere. As a hypothetical example it presents an existing pseudo-ecosystem of manufacturing that has real windows of opportunity to increase its share in the global materials production industry, even in highly industrialized countries. As a suggestion and example the author point out possibilities to almost fulfill the proposed simple rules to be considered inside an ecosystem of manufacturing utilizing the production of steel via biomass versus fossil coal. A relevant and difficult rule to be attained in a quasi-ecosystem of manufacture is to be a near zero atmosphere oxygen depletion integrated process. The industrial alternatives that utilizes the actual photosynthesis are the ones that can reach a higher ecosystem of manufacture's index. It is presented an ideal integrated steelmaking process where the gaseous, liquids and solid residues generated in one part of the system are or can be utilized in the other parts of the same system. A potential ecosystem of manufacture to produce primary iron is illustrated in the paper.

Keywords: Oxygen depletion; Carbon Capture and Storage; Ecofriendly steel; Clean and Zero $\mathrm{CO}_{2}$ Emission; Biomass Based Ironmaking.
\end{abstract}

1 Metallurgical Engineer, Ph. D, CEO - RSConsultants Ltda. 


\section{INTRODUCTION}

Clean industrial process and what can be considered a manufacture ecosystem may be a complex definition. This work shows some simple examples and definitions in this subject, aiming to ignite real opportunities to provide more job positions and better global environment conditions.

The paper main contribution is to call attention for the oxygen depletion as another way to look for Global Warming. The fossil energy will be present for many years and its negative effects to the Global environment can be counter measured by the use of larger proportions of photosynthesis based industrial process. The nature has its own oxygen recovery tools but its kinetics does not meet the necessary rate to bring it to a more stable environment. Therefore, increasing the processes oxygen rate recovery is a way to bring a better chemistry to the atmosphere.

The real example from a Brazilian pseudo-ecosystem to steel production directly from iron ore is utilized from literature data and previous papers of this author.

\section{MATERIAL AND METHODS}

\section{SIMPLE RULES FOR AN ECOSYSTEM OF MANUFACTURE}

In this paper the following assumptions for what is a clean industrial process and what can be considered inside a manufacture ecosystem are given.

a) Clean industrial process: This process is able to operate inside a system where all its major impacts on atmosphere, land and water resources are the lowest possible under actual technological status. Its major impacts are in the depletion of natural resources such as iron ore, limestone and water, aiming to transform them into human goods. This process will be considered $100 \%$ clean when it has no solid, liquid and gaseous wastes. Waste is the natural resources leaving a system without being reutilized again inside the same defined integrated system.

b) Ecosystem of manufacture: This methodology makes a clean industrial process. The raw materials and products are considered a necessary environmental impact for human living but it is not permitted to generate any kind of solid, liquid and gaseous wastes beyond their borders. The production has to follow a path where no used materials are co-products recycled inside the boundaries of manufacture ecosystem.

c) Manufacturing ecosystem boundaries: It is the minimum number of activities fulfilled by an integrated industry in such way that land area, natural resources and process operations are able to recycle all of the system wastes inside their borders.

Most kind of industrial process can reach a certain level of cleanness under the above assumptions. Among the existing process, the ones that can almost reach the level of $100 \%$ cleanness are based on renewable energy coming from the photosynthesis, which is the only way to regenerate oxygen while $\mathrm{CO}_{2}$ is removed from atmosphere.

A good example of a clean industrial process is the steel production from sustainable fresh carbon production by photosynthesis. This route may become the cleanest 
possible to be conceived because it does not deplete the atmosphere of oxygen nor increase it with $\mathrm{CO}_{2}$. Besides, it is able to recycle almost $100 \%$ of its solid, liquid and gaseous wastes (co-products) inside its boundaries. In this work, as a demonstration of a pseudo eco-manufacture process, it will be shown an existing industrial route to steel production.

\section{RESULTS AND DISCUSSION}

\section{$\mathrm{CO}_{2}$ EMISSION REDUCTION OR OXYGEN DEPLETION AVOIDANCE?}

Fossil fuels based industrial process will always have a more complex task to reach high levels of manufacture ecosystem. However, they will be here for many years to come but everyone should work to avoid oxygen depletion and the use of fossil energy, in order to come in equilibrium with the zero oxygen depletion processes such as the biomass based ones.

Fossil based industrial processes hardly fulfills the manufacture ecosystem's principles because of two main reasons:

a) $\mathrm{CO}_{2}$ increase: $\mathrm{CO}_{2}$ and other global warming gases have permanent negative effect in global atmosphere. They cannot recover at the necessary earth natural recovery rate as oxygen is removed from it. To utilize Carbon Capture and Storage possibilities it is not a solution for $\mathrm{CO}_{2}$ reduction since the $\mathrm{CO}_{2}$ "stored" is also storing the $\mathrm{O}_{2}$ removed from the atmosphere, e.g., the relative concentration of the atmosphere other gases increases including the remaining $\mathrm{CO}_{2}$ that already was there.

b) $\mathrm{O}_{2}$ depletion: when a fossil resource is burnt $\mathrm{O}_{2}$ is removed from the atmosphere in amounts higher than the $\mathrm{CO}_{2}$ mass released into the atmosphere, as can be seen in the Figure 1 (1) from real measured data. In the nineties the rate of oxygen reduction, depletion, from the atmosphere was in the order of $2.13 \mathrm{ppm}$ of $\mathrm{O}_{2}$ (depletion) for each $1 \mathrm{ppm}$ of $\mathrm{CO}_{2}$ increased in the atmosphere as shown in the slop of the linear curve of Figure 1 values.

One of the possibilities to increase the $\mathrm{O}_{2}$ recovery ratio in order to balance the $\mathrm{CO}_{2}$ molecules excess generation rate is to better manage the use of biomass based materials, intensifying it, as well as its share of the global energy matrix. 


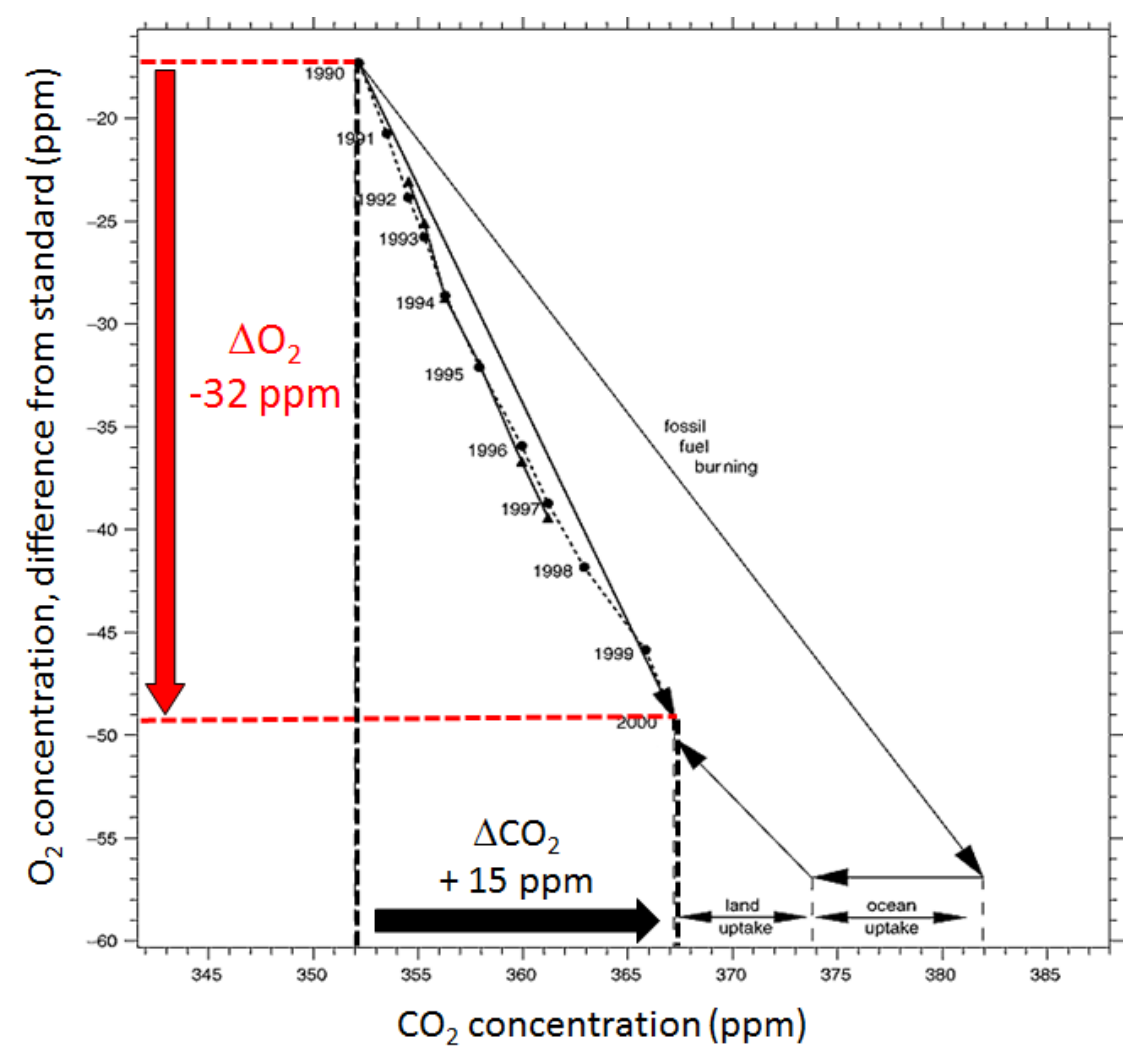

Figure 1. Partitioning of fossil fuel $\mathrm{CO}_{2}$ uptake using $\mathrm{O}_{2}$ measurements ${ }^{1}$.

On the industrial view, the use of biomass in metal production is an existing and strong possibility to reach this ratio in order to reduce the oxygen depletion. As an example, Brazil produces steel directly from actual sustainable biomass and contributes to nonoxygen depletion ratio increase. Many other Planet regions are able to become huge biomass users and producers.

\section{INDUSTRIAL PROCESS WITH ALMOST ZERO OXYGEN CONSUMPTION}

The industrial processes directly connected to biomass production are oxygen depletion processes. As explained previously, they have the least $\mathrm{CO}_{2}$ emissions impact to the Planet Earth. Almost one third of the Brazilian iron production is from sustainable wood. It has the lowest oxygen consumption and $\mathrm{CO}_{2}$ emission in the metals industry. Any other industry which is able to incorporate renewable biomass fraction sources in its production cycle is contributing to reduce oxygen depletion and $\mathrm{CO}_{2}$ emission.

The use of wood as a reducer energy source to produce steel consume zero oxygen and it is a zero $\mathrm{CO}_{2}$ emission process, since it is based on the photosynthesis as can be demonstrate with the net chemical equation. The symbol hv is used to depict the energy input from sunlight. The chemical equation [1], however, is a simplification of the complex chemical reactions series that photosynthesis involves (2):

$$
\mathrm{nCO}_{2}+\mathrm{nH}_{2} \mathrm{O}+h v-->\left(\mathrm{CH}_{2} \mathrm{O}\right)_{\mathrm{n}}+\mathrm{nO}_{2}
$$

Where $\mathbf{n}$ is the number of moles. 
It is important to emphasize that the number of moles of $\mathrm{CO}_{2}$ removed from the atmosphere (44 grams) is equal the number of moles of oxygen released to the atmosphere (32 grams). The typical stoichiometry to represent cellulose is $\mathrm{C}_{6} \mathrm{H}_{10} \mathrm{O}_{5}$ that also can have its net formation from $\mathrm{CO}_{2}$ sequestration with one $\mathrm{O}_{2}$ molecule released as shown in equation [1].

\section{SUSTAINABLE EXAMPLES OF BLAST FURNACE $\mathrm{O}_{2}$ DEPLETION AND $\mathrm{CO}_{2}$ EMISSIONS REDUCTIONS}

From wood logs, wood wastes and biomass wastes it is possible to produce lump charcoal as well as charcoal fines from biomass. There is a growing demand for coal fines to be used in combustion, pelletizing plants and pulverized coal injection in blast furnaces. It is a new opportunity window to use renewable carbon source such as charcoal.

The production of charcoal fines for conventional coke based integrated mills can reduce significantly the $\mathrm{CO}_{2}$ emissions as well as improve the hot metal quality in a coke based Blast Furnace. Figure 2, from Sampaio(3) shows the average emissions of a typical integrated production of hot metal through the following operational modes:

Mode 1: The reference mode. It is a traditional $100 \%$ coke based Blast Furnace operating with $440 \mathrm{~kg}$ of fixed carbon in coke per metric ton of hot metal. The metallic burden for all modes is kept constant with $50 \%$ pellet and $50 \%$ lump iron ore. This mode shows a total $\mathrm{CO}_{2}$ emission of $2 \mathrm{t} / \mathrm{t} \mathrm{HM}$ (Hot Metal) and $1 \mathrm{t} / \mathrm{t} \mathrm{HM}$ of oxygen consumption. Mode 2: Part of the coke from the reference mode was replaced with $160 \mathrm{~kg} / \mathrm{t} \mathrm{HM}$ of pulverized coal injection, assuming a coke/coal replacement ratio of 1 . The $\mathrm{CO}_{2}$ emissions were reduced to $1.8 \mathrm{t} / \mathrm{t} \mathrm{HM} \mathrm{(10 \%} \mathrm{reduction)} \mathrm{and} \mathrm{oxygen} \mathrm{consumption} \mathrm{to} 0.87$ t/t HM.

Mode 3: The $160 \mathrm{~kg}$ of coal/t HM from mode 2 was replaced by natural gas (NG) injection. The assumed replacement ratio was $1.28 \mathrm{~kg}$ of coke to $1 \mathrm{Nm}^{3}$ of NG. In operational practice this value is normally lower and can reach values up to 0.8 . The $\mathrm{CO}_{2}$ emission was reduced to $1.7 \mathrm{t} / \mathrm{t} \mathrm{HM} \mathrm{(15 \%} \mathrm{reduction)} \mathrm{and} \mathrm{oxygen} \mathrm{consumption} \mathrm{to}$ $0.86 \mathrm{t} / \mathrm{t} \mathrm{HM}$.

Modes 4 and 5: Part of the lump coke from reference mode was replaced by 5 and $10 \%$ charcoal in one by one ratio. The $\mathrm{CO}_{2}$ emission was reduced to 1.9 and $1.8 \mathrm{t} / \mathrm{t} \mathrm{HM}$ (5 and $10 \%$ reduction).

Modes 6 and 7: Pulverized coal injection from reference mode was replaced by pulverized charcoal injection. Mode 6 is $160 \mathrm{~kg} / \mathrm{t} \mathrm{HM}$ charcoal injection and Mode 7 with $210 \mathrm{~kg}$ charcoal $/ \mathrm{t} \mathrm{HM}$. The coke/charcoal fines replacement ratio was considered $1 / 1$ for $160 \mathrm{~kg} / \mathrm{t} \mathrm{HM}$ and $0.9 / 1$ for the $210 \mathrm{~kg} / \mathrm{t} \mathrm{HM}$. The $\mathrm{CO}_{2}$ emission was reduced to $1.33 \mathrm{t}$ $\mathrm{CO}_{2} / \mathrm{t} \mathrm{HM} \mathrm{(33 \%} \mathrm{reduction)} \mathrm{for} \mathrm{the} 160 \mathrm{~kg}$ of charcoal from renewable biomass and to $1.2 \mathrm{t} \mathrm{CO}_{2} / \mathrm{t} \mathrm{HM}$ for the $210 \mathrm{~kg}$ charcoal fines/t $\mathrm{HM}$ (40\% reduction).

Modes 8: Fix carbon consumption is the same from reference mode. However, $100 \%$ lump charcoal and $100 \mathrm{Nm}^{3}$ of $\mathrm{NG} / \mathrm{t} \mathrm{HM}$ equivalent to Mode 8 were considered. The $\mathrm{CO}_{2}$ emission reduced to $0.3 \mathrm{t} / \mathrm{t} \mathrm{HM}$, representing $85 \%$ reduction in $\mathrm{CO}_{2}$ emission.

Mode 9: The same fix carbon from reference with $100 \%$ charcoal based Blast Furnace. There is a negative reduction value in $\mathrm{CO}_{2}$ emission due to the carbon leaving the hot 
metal and very low oxygen consumption. In all examples the BF off gas is complete combusted.

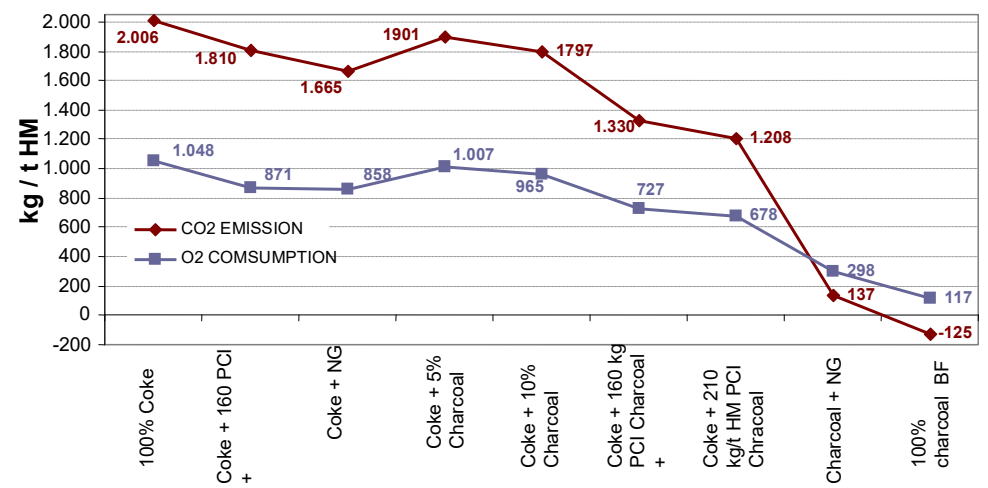

Figure 2. $\mathrm{CO}_{2}$ emission and $\mathrm{O}_{2}$ consumption in the nine simulated modes ${ }^{(3)}$.

Those modes cover a wide possibilities range to reduce $\mathrm{CO}_{2}$ emissions in an integrated mill and also increase metallurgical benefits due to the basic nature of the charcoal ash and its extremely lower sulfur content when compared to coal/coke.

Biomass is a zero $\mathrm{CO}_{2}$ emission source that also regenerates all the oxygen, returning it back to the atmosphere as $\mathrm{CO}_{2}$. Besides, charcoal fines injection of $210 \mathrm{~kg} / \mathrm{t} \mathrm{HM}$ into a coke based Blast Furnace inside an integrated mill reduces $\mathrm{CO}_{2}$ emissions up to $40 \%$.

\section{THE BIOMASS BASED BRAZILIAN STEEL PRODUCTION - A PSEUDO- ECOSSYSTEM OF MANUFACTURE}

The present status of the Brazilian biomass based steel production is moving to a true ecosystem of manufacturing. Because it is a sustainable biomass based production, most of its wastes become co-products that may be used inside of the integrated production cycle.

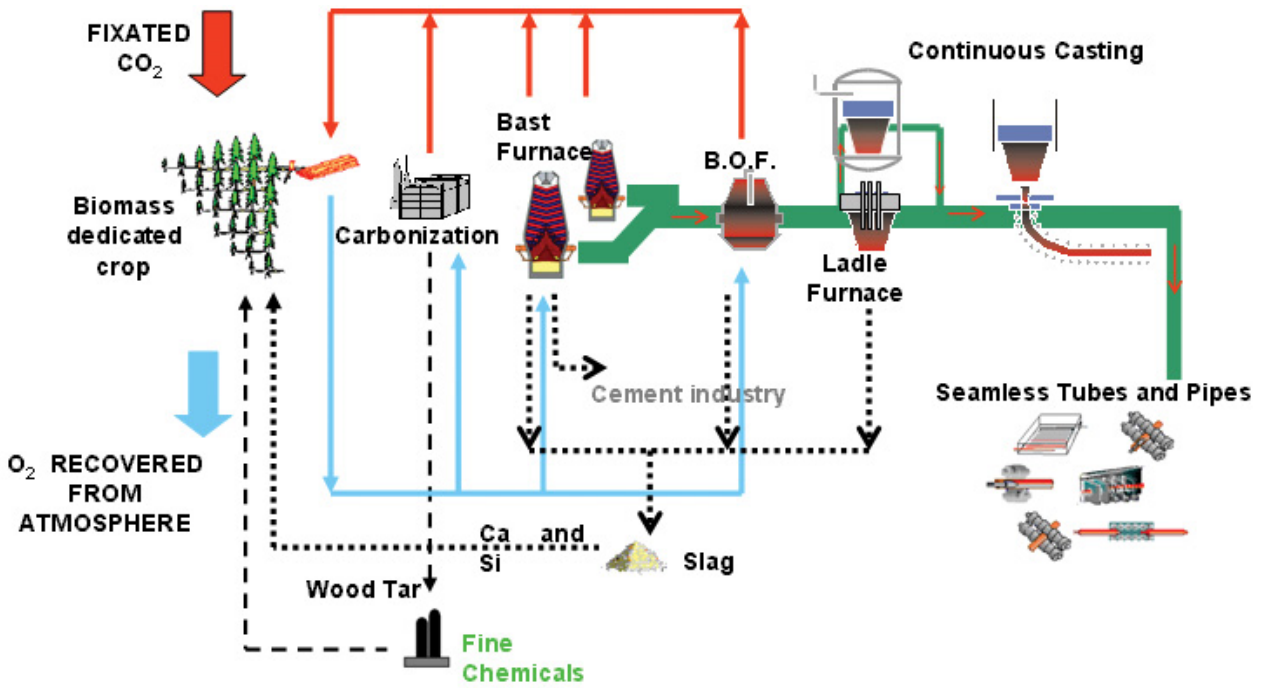

Figure 3. Schematic illustration of biomass based seamless steel tube production ${ }^{(5)}$. 
Figure 3 (4 and 5) illustrates the whole integrated production cycle. In the illustrated cycle, almost all residues can be technically recycled inside the system. The waste generated in one part of the system can be utilized in another part.

Tables 1, 2 and 3 summarize the major residues and co-products for the cycle shown in Figure 3. Additional technologies starting at forest plantation, forest harvesting, wood cutting and handling, wood carbonization, charcoal handling and transportation, charcoal beneficiation up to the iron and steel mill are being addressed in parallel for this real example.

Concerning the carbonization step, the highest actual impact in the farmland area is the huge amount of volatile matter released to atmosphere. It is an energy lost of $45 \%$ and mass lost of $65 \%$ from the original wood. To eliminate this impact it is necessary to introduce more expensive and more efficient technologies into the integrated system.

Bark \& small branches and leaves stay on the soil for micro nutrients recovery. It helps soil moisture retention and protection against direct sunlight. This material will also be burnt at the boiler kiln to generate electricity. The ash (plant nutrients) will return to the forest land.

Continuous Carbonization process: this technology aims to eliminate the huge mass and energy wastes. In the traditional brick kiln almost $2 / 3$ thirds of the wood mass and $45 \%$ of its original energy is lost to environment with additional $\mathrm{CH}_{4}$ emission in the order of $52 \mathrm{~kg} / \mathrm{t}$ of charcoal (equivalent to $1100 \mathrm{~kg}$ of $\mathrm{CO}_{2} / \mathrm{t}$ charcoal).

The process produces a very homogeneous charcoal and is able to recover part of its volatile matter energy to cogenerate electricity to dry the small wood logs. Other very attractive technology is the DPC process where the roll-on principle is utilized to bring wood wastes from generation sites. The drying and charcoal production steps are done in different moments in a reactor from a series of others in order to transfer energy excess from one reactor to the other up to the charcoal cooling stage ${ }^{(6)}$.

Table 1. The forest and carbonization residues and their major vectors in the manufacture ecosystem principle.

\begin{tabular}{|c|c|c|c|c|c|c|}
\hline \multirow{5}{*}{ 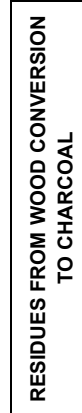 } & SOURCE & $\begin{array}{c}\text { ACTUAL } \\
\text { DESTINATION }\end{array}$ & IMPACT & $\begin{array}{l}\text { INSIDE OR } \\
\text { OUTSIDE } \\
\text { SYSTEM } \\
\end{array}$ & $\begin{array}{l}\text { ECOMANUFACTURE } \\
\text { DESTINATION }\end{array}$ & SUSTAINABILITY TODAY? \\
\hline & Wood bark and saw mill & $\begin{array}{l}\text { Stay in the } \\
\text { plantation soil }\end{array}$ & $\begin{array}{l}\text { Soil protection, micro } \\
\text { nutrients retention but } \\
\text { possible methane } \\
\text { emissions when putrefied. }\end{array}$ & Inside & $\begin{array}{c}\text { yes but better destination should be } \\
\text { considered to avoid methane } \\
\text { emission. }\end{array}$ & $\begin{array}{c}\text { yes but can improve the } \\
\text { environmental impact with } \\
\text { destination as biofuel when its } \\
\text { economicity becomes attractive }\end{array}$ \\
\hline & $\begin{array}{l}\text { Wood water from charcoal } \\
\text { making }\end{array}$ & Atmosphere & Smog & Inside & $\begin{array}{l}\text { Medium for acid foliar fertilizer } \\
\text { application. }\end{array}$ & $\begin{array}{l}\text { No - need to be recovered or } \\
\text { complete combusted. }\end{array}$ \\
\hline & $\begin{array}{c}\text { Wood tar from charcoal } \\
\text { making }\end{array}$ & Atmosphere & Smog & Inside & $\begin{array}{l}\text { Boil, food industry, bio pitch, } \\
\text { organic fertilizer }\end{array}$ & $\begin{array}{l}\text { No - need to be recovered or } \\
\text { complete combusted. }\end{array}$ \\
\hline & $\begin{array}{c}\text { Methane from carbonization } \\
\text { volatiles }\end{array}$ & Atmosphere & $\mathrm{CO} 2$ increase & Inside & $\begin{array}{l}\text { Fuel off processes that uses the } \\
\text { volatile matter fraction of the } \\
\text { carbonization. }\end{array}$ & $\begin{array}{l}\text { No -need to be combusted or } \\
\text { avoided in another existing } \\
\text { charcoal making technology. }\end{array}$ \\
\hline
\end{tabular}


Table 2. The iron making residues and its major vectors in the manufacture ecosystem principle.

\begin{tabular}{|c|c|c|c|c|c|c|}
\hline \multirow{4}{*}{ 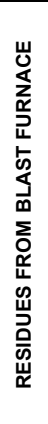 } & SOURCE & $\begin{array}{c}\text { ACTUAL } \\
\text { DESTINATION }\end{array}$ & IMPACT & $\begin{array}{c}\text { INSIDE OR } \\
\text { OUTSIDE } \\
\text { SYSTEM }\end{array}$ & $\begin{array}{l}\text { ECOMANUFACTURE } \\
\text { DESTINATION }\end{array}$ & SUSTAINABILITY TODAY? \\
\hline & Slag & Cement industry & $\begin{array}{c}\text { Water consumption during } \\
\text { granulation }\end{array}$ & Outside & $\begin{array}{l}\text { Yes- It is a Ca } \mathrm{Ca}^{* *}, \mathrm{Mg}^{* *},(\mathrm{SiO} 4) 3- \\
\text { source for soil acidity correction. } \\
\text { Highly necessary in the Brazilian } \\
\text { Savannas soil and avoids } \mathrm{CO} 2 \\
\text { emission from limestone. }\end{array}$ & $\begin{array}{l}\text { Yes if it can compete with } \\
\text { limestone and dolomite fines that } \\
\text { can be cheaper in the regions } \\
\text { where the forests are planted. }\end{array}$ \\
\hline & BF off gas sludge. & Land fill & Land fill area & Outside & $\begin{array}{l}\text { Yes -lt is excellent for soil } \\
\text { conditioning and water and oxygen } \\
\text { retention. Low calorific renewable } \\
\text { fuel for red ceramic industry. }\end{array}$ & $\begin{array}{l}\text { Yes- there are environmental } \\
\text { regulations for biomass only dust } \\
\text { and sludge in the agriculture. } \\
\text { Freight is the major decision } \\
\text { point. Can be recycled in one In- } \\
\text { House Pellet plant. }\end{array}$ \\
\hline & $\begin{array}{c}\text { BF area dust from dedusting } \\
\text { filters bags }\end{array}$ & $\begin{array}{l}\text { Injection at BF } \\
\text { tuyeres }\end{array}$ & None & Inside & Yes & Yes. \\
\hline
\end{tabular}

The three major iron making residues shown in Table 2 have the potential to be recycled in the integrated system. However, other options are being more economically attractive such as granulated slag to the cement industry instead of using it as soil conditioner in the eucalyptus forest plantation.

The BF off gas dust and sludge from the dry and wet cleaning systems are currently sent to the official landfill area with costs. Recent environmental regulation open the opportunity for this material from $100 \%$ charcoal BF to be transferred back to the farmland areas, where it is used as soil conditioning and acidity reduction, red ceramic brick manufacture for fuel and pigment source.

The best option selected for high value residues reuse was the construction of an in house pellet plant with $1.4 \mathrm{Mt} / \mathrm{year}$ of BF pellet. Residues with significant amount of iron, carbon and lime are reutilized as co-products in the integrated system.

Table 3. The steelmaking residues and its major vectors in the manufacture ecosystem principle.

\begin{tabular}{|c|c|c|c|c|c|c|}
\hline \multirow{5}{*}{ 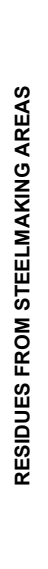 } & SOURCE & $\begin{array}{c}\text { ACTUAL } \\
\text { DESTINATION }\end{array}$ & IMPACT & $\begin{array}{l}\text { INSIDE OR } \\
\text { OUTSIDE } \\
\text { SYSTEM } \\
\end{array}$ & $\begin{array}{l}\text { ECOMANUFACTURE } \\
\text { DESTINATION }\end{array}$ & SUSTAINABILITY TODAY? \\
\hline & Steel making slags & $\begin{array}{c}\text { Agriculture as } \\
\text { Silicates source and } \\
\text { acidity correction. }\end{array}$ & $\begin{array}{l}\text { Dust during handling and } \\
\text { beneficiation }\end{array}$ & $\begin{array}{l}\text { Inside and } \\
\text { sold to } \\
\text { market }\end{array}$ & $\begin{array}{l}\text { Yes / Not yet } 100 \% \text {. Other } \\
\text { applications compete with its } \\
\text { ecological destination. }\end{array}$ & $\begin{array}{c}\text { Yes if it can compete with } \\
\text { limestone fines near the use } \\
\text { source in the eucalyptus forests. }\end{array}$ \\
\hline & Used refractory & $\begin{array}{c}\text { Sold to steelmaking } \\
\text { flux processing } \\
\text { industry }\end{array}$ & None & Outside & $\begin{array}{l}\text { Yes - Can be utilized as Mg2+ as } \\
\text { macronutrients in agriculture. Need } \\
\text { to be milled to fines. }\end{array}$ & $\begin{array}{l}\text { Yes if can compete with other } \\
\text { sources of } \mathrm{Mg} 2+\text { such as } \\
\text { dolomite fines and fines from } \\
\text { metallic Mg production. }\end{array}$ \\
\hline & Scale & Sold to scrap dealer & $\begin{array}{l}\text { Oily scale need to be } \\
\text { calcined to remove oil. }\end{array}$ & Outside & $\begin{array}{c}\text { Yes- if the integrated system has a } \\
\text { agglomeration process. The In- } \\
\text { House-Pellet Plant is being built } \\
\text { that will utilize this excellent iron } \\
\text { source. } \\
\end{array}$ & $\begin{array}{l}\text { Yes if there is and agglomeration } \\
\text { plant inside the system to use it. }\end{array}$ \\
\hline & BOF sludge \& dust & To landfill & landfill area & Outside & $\begin{array}{l}\text { Yes- if there is no } \mathrm{Cd} \text { or } \mathrm{Pb} \text { in the } \\
\text { sludge's because it does utilizes } \\
\text { outside scrap. It can be utilized as } \\
\text { a soil basicity correction and } \\
\text { source of } \mathrm{Mg}, \mathrm{P}, \mathrm{Si} \text { and } \mathrm{Ca} \text {. }\end{array}$ & $\begin{array}{l}\text { Yes if can compete with local } \\
\text { supply of equivalent sources. It } \\
\text { will be utilized in the IHP plant as } \\
\mathrm{CaO} / \mathrm{MgO} \text { and Fe sources. }\end{array}$ \\
\hline
\end{tabular}

This example taken from an existing integrated system ${ }^{(5)}$ is becoming a real ecosystem of manufacture under the simple premises assumed in this paper. The intention is to motivate the research to look for a better design of Eco manufacturing systems. 


\section{CONCLUSIONS}

- The claimed Carbon Capture and Storage (CCS) option to reduce $\mathrm{CO}_{2}$ emissions from fossil fuels is a mistaken method since it will not avoid the $\mathrm{CO}_{2}$ concentration increase and it does not allow oxygen recovery to atmosphere by photosynthesis.

- The fossil energy source will be present for many years. In order to neutralize its negative impacts in the Planet it is necessary to increase the share of photosynthesis based energy sources and accelerates its oxygen recovery.

- The existing method to balance the oxygen depletion is to increase the rate of photosynthesis based processes. This paper presented one real example from Brazil in iron and steel production that is almost zero oxygen depletion.

- The biomass example used in an existing coal based integrated mill demonstrate that partial utilization can be a solution in other regions to reduce oxygen depletion and $\mathrm{CO}_{2}$ emissions. For the existing coal based processes, any substitution of fossil fuels by a biomass source will contribute significantly to avoid oxygen depletion.

- The steel industry has a high recycling rate of its products. This paper presented some real facts showing that residues generated inside the industry have conditions to be reused inside its integrated system under the sustainability criteria. Among the existing steel process, the biomass based production sustainable process fulfills most of the eco-manufacture criteria.

- The industrial processes that are strongly dependent of photosynthesis are able to better fulfill the proposed simple rules to be considered an ecosystem of manufacture. Therefore, a process under ecosystem manufacture principle has the lowest atmospheric oxygen depletion capability.

\section{REFERENCES}

1 Solomon S., et al. Contribution of Working Group Ito the Fourth Assesment Report of Intergovernamental Panel on Climate Change, Cambridge University Press, Cambridge, United Kingdom and New York, NY, USA. http://www.ipcc.ch/ipccreports/tar/wg1/fig34.htm.

2 Foyer, Christine H. (1984). Photosynthesis. New York: Wiley. Govindjee, and Coleman, W. J. (1990). "How Plants Make Oxygen." Scientific American 262:50-59. ).

3 Sampaio, R, S and Silveira, M., L., Conventional ways to reduce $\mathrm{CO}_{2}$ emissions in Blast Furnace in Integrated Steel Mills. 4 th. IAS Ironmaking Conference, 2003, San Nicolas, Argentina.

4 SAMPAIO, R. S. Produção de Metais com Biomassa Plantada. In: MELLO, Marcelo Guimarães (Org). Biomassa - energia dos trópicos em Minas Gerais. Belo Horizonte: LabMidia/FAFICH, 2001, p.163-178.

5 Branco, M.A.S.C., Silva, L.B., Oliveira, AC., Sampaio, R.S., Silveira, M.L. Biosteel: A SelfSustainable Solution to Produce Seamless Steel Tubes Directly from Planted Biomass. Bioenergy 2002 - Bioenergy for the Environment, Sep. 22-26, 2002 - Boise, Idaho, USA.

6 Lucio, A.; Sampaio, R. S., Technical contribution to the $2^{\text {nd }}$ International Meeting on Ironmaking, September 12 to 15, 2004 - Vitória - ES - Brazil. Ronaldo@issbrazil.org. 